\title{
Single staple tissue preserving excision of intraluminal gastric GIST-preliminary case series
}

\author{
Francesco Di Maggio ${ }^{1,2}$, James A. Gossage ${ }^{1,2}$ \\ ${ }^{1}$ Upper Gastrointestinal Surgery, Guy's and St Thomas' NHS Foundation Trust, London, UK; ${ }^{2}$ Section of Gastrointestinal Cancer, Division of \\ Cancer Studies, King's College London, UK \\ Correspondence to: Mr. James A. Gossage, MBBS, BSc, MS, FRCS. Department of Surgery, St Thomas Hospital, Westminster Bridge Road, SE17EH \\ London, UK. Email: james.gossage@gstt.nhs.uk.
}

\begin{abstract}
Gastro-intestinal stromal tumours (GISTs) should be resected preserving as much healthy tissue as possible while minimizing potential tumour cells dissemination. Minimally invasive wedge resection is described as a safe technique but often results in resection of an excessive amount of healthy tissue. We use an effective and easily reproducible minimally invasive technique to reduce complications due to unnecessary staple lines while preserving healthy tissue, which we describe in an educative video. This preliminary series reports the first four consecutive patients who underwent a GIST resection performed using this technique. All four patients had endoluminal gastric GISTs and were operated by the same team at the same institution (St Thomas Hospital - Guys and St Thomas NHS Foundation Trust, London) between 2018 and 2020. The technique was specifically used for endophytic bulky tumours. Average operating time was 95 minutes. Median hospital stay was two days. No significant peri- or post-operative complication was recorded and the quality of the surgical specimens was adequate. Follow up reflected UK national guidelines on GISTs according to pathological risk stratification. Single staple tissue preserving excision is a valuable and safe "no touch" technique to resect endophytic gastric GISTs and other submucosal tumours.
\end{abstract}

Keywords: Gastro-intestinal stromal tumour (GIST); case series; laparoscopy; staple line

Received: 13 April 2020; Accepted: 26 November 2020; Published: 20 October 2022.

doi: $10.21037 /$ jovs-20-103

View this article at: https://dx.doi.org/10.21037/jovs-20-103

\section{Introduction}

Although rare, Gastro-intestinal stromal tumours (GISTs) are the most common tumours of mesenchymal origin in the gastrointestinal tract $(1,2)$. They can occur anywhere throughout this tract, but the most common location is the stomach. Considering these tumours rarely metastasize to nearby lymph node stations, it is recommended that GISTs undergo complete surgical resection with macroscopically negative margins. Minimally invasive wedge resections have been described as feasible and safe $(3,4)$. However, the former often require removal of a large amount of excess healthy tissue, which can result in narrowing and tortuosity of the remnant lumen. Eversion method through a gastrotomy has been previously described as an effective technique, even for large endophytic tumours $(4,5)$. However, each staple line in the stomach carries additional risks for post-operative complications (6), such as intraluminal bleeding, leak and stenosis. The risk of tumour cells dissemination during the resection also needs to be considered and an ideal operation has to limit specimen handling as much as possible. We hereby present a tissue preserving technique, which is also suitable for large/bulky tumours. We present the following article in accordance with the AME Case Series reporting checklist (available at https://jovs.amegroups.com/article/view/10.21037/jovs-20$103 / \mathrm{rc})$.

\section{Case presentation}

We have to date successfully performed four consecutive GIST resections (2 F, 2 M, Table 1) using the described technique. Surgery was performed at St Thomas Hospital 
Table 1 Patients characteristics. Four patients were successfully treated with this technique to date, with characteristics as summarized

\begin{tabular}{|c|c|c|c|c|c|c|c|c|c|}
\hline Patients & Sex & Age & Site of GIST & OGD & Approach & ASA & Complications & $\begin{array}{l}\text { Operating } \\
\text { time (min) }\end{array}$ & $\begin{array}{l}\text { Hospital } \\
\text { stay (day) }\end{array}$ \\
\hline 1 & $\mathrm{M}$ & 75 & $\begin{array}{l}\text { Upper } \\
\text { body/greater } \\
\text { curvature }\end{array}$ & $\begin{array}{l}\text { Polypoid lesion with } \\
\text { central ulceration }\end{array}$ & LAP & 2 & 0 & 95 & 2 \\
\hline 2 & $\mathrm{M}$ & 71 & Lesser curvature & & LAP & 2 & 0 & 105 & 2 \\
\hline 4 & $\mathrm{~F}$ & 68 & Body/antrum & $\begin{array}{l}4 \mathrm{~cm} \text { ulcerated } \\
\text { subepithelial lesion }\end{array}$ & LAP & 2 & 0 & 94 & 1 \\
\hline
\end{tabular}

GIST, gastro-intestinal stromal tumour; OGD, Oesophago-Gastro-Duodenoscopy; LAP, laparoscopic surgery; OPEN, open surgery; ASA, American Society of Anesthesiologists.

(Guys and St Thomas NHS Foundation Trust, London) by the same surgeon. Data were collected prospectively. Three cases were performed laparoscopically, one was an open gastric resection, to treat an incisional hernia at the same time. Patients' age was $74 \pm 6$ years. All patients had an endoscopy (OGD) with biopsies and a CT of the abdomen to stage the disease; the decision to operate was made after multidisciplinary team discussion. Inclusion criteria was the presence of an endophytic gastro intestinal stromal tumour (GIST). Two patients had a greater curvature lesion, one had a $7 \mathrm{~cm}$ GIST of the lesser curvature, and one had a GIST of the antrum (Figure 1). All surgery was performed electively in the last 18 months. Patients were kept nil by mouth the day before surgery and VTE prophylaxis was administered in the form of subcutaneous 5,000 U of Dalteparin. Patients were followed up in clinic 8-12 weeks after discharge.

All procedures performed in this study were in accordance with the ethical standards of the institutional and/or national research committee(s) and with the Helsinki Declaration (as revised in 2013). Written informed consent was obtained from the patients.

\section{Surgical procedure (laparoscopic) (Video 1)}

Patient is in supine position. A 12-mm optical port is inserted in the left upper quadrant and pneumoperitoneum induced. Omental adhesions are dissected from the abdominal wall so that three more ports (umbilical, right and left paramedian) can be inserted and Nathanson liver retractor positioned.

A breach is made in the gastro-colic ligament and lesser sac is entered. Dissection proceeds along the greater curvature up to $3 / 4$ of the stomach length. A 5 -cm lesion is identified in the posterior wall. The posterior wall of the stomach is further mobilised above the pancreas until reaching the gastro-hepatic ligament.

A vertical gastrotomy is made adjacent to the GIST with Ultrasonic device. Mobilization of the stomach shall be made according to CT findings to optimize the view, and intraoperative endoscopy, when in doubt, can be useful adjunct to identify/mark the tumour edges before the gastrotomy is made. The tumour is then exteriorised. Two staying sutures are put at the edges of the gastrotomy to facilitate stomach mobilisation during the stapling time with a "no touch" technique. Echelon 45 linear stapler is used to excise the tumour and the previous gastrotomy at the same time, leaving a single line of staples. Specimen is extracted on an endo-catch from an enlarged LUQ incision after haemostasis is checked. To reduce even further the risk of tumour cell seeding into the abdominal cavity, the endo-catch bag can be positioned to cover the tumour immediately after its mobilisation and eversion, before the stapling time. Liver retractor and ports are extracted under direct vision. 0-J Vicryl is used to suture the fascia and 3/0 Monocryl to skin. No naso-gastric tube or intra-abdominal drainage was considered necessary.

\section{Results}

All four patients had a smooth recovery, with a median hospital stay of 2 days. Intraoperative blood loss was 

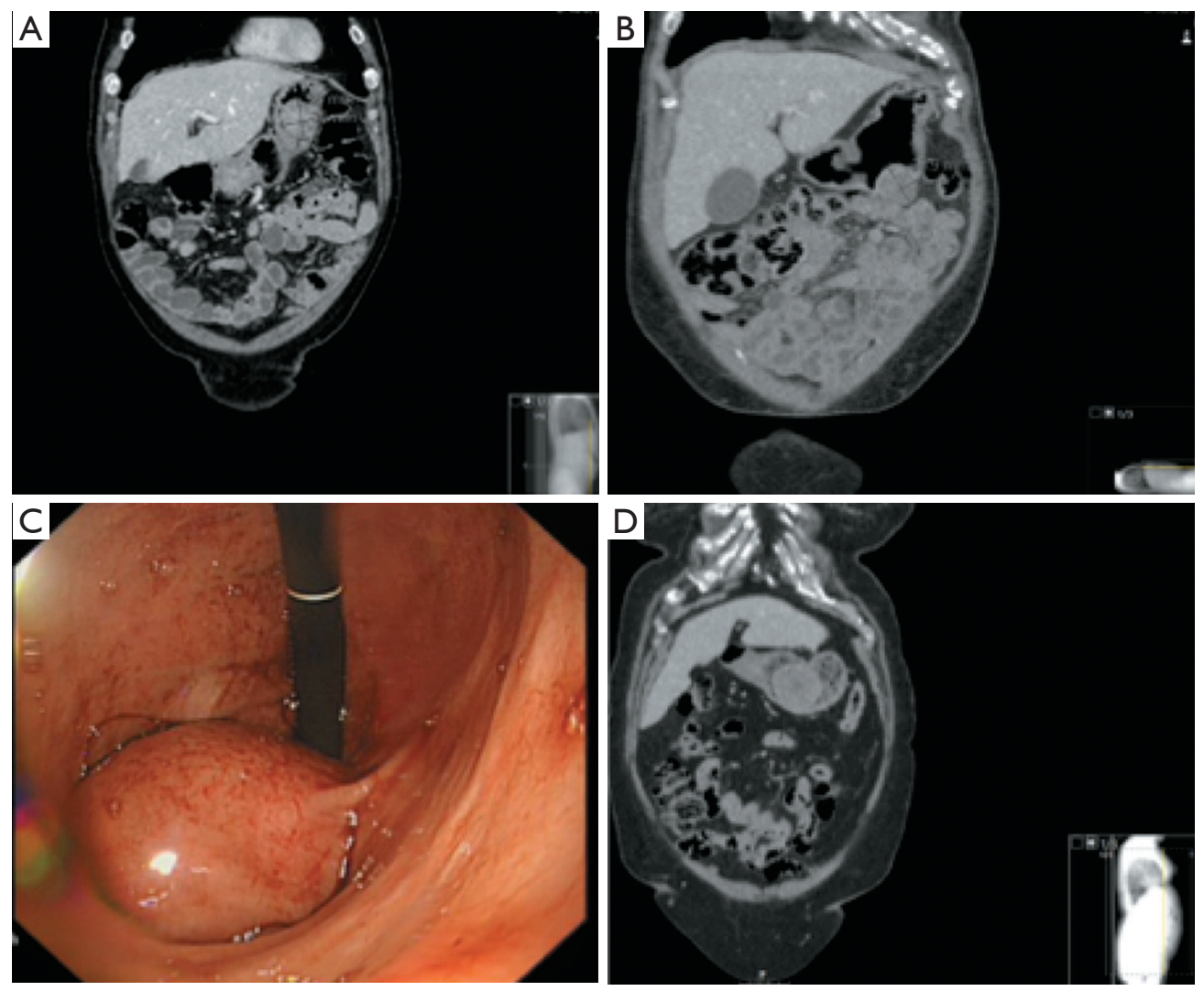

Figure 1 Single staple excision can be performed for endophytic tumours localized in different areas of the stomach. (A) CT showing $38 \mathrm{~mm} \times 35 \mathrm{~mm}$ GIST at the upper body/greater curvature in patient 1; (B) patient 2 had a lesion of the lower body of $34 \mathrm{~mm}$; (C) endoscopic appearance of pedunculated GIST of the lesser curvature (patient 3); (D) GIST of the antrum (CT). GIST, gastro-intestinal stromal tumour.

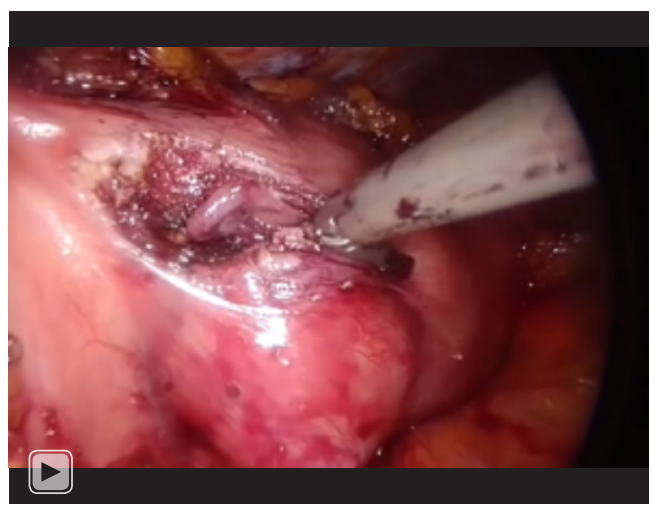

Video 1 Single staple tissue preserving excision of intraluminal gastric GIST. GIST, gastro-intestinal stromal tumour.

consistently $<100 \mathrm{~mL}$. On post-operative day one, clear fluids were started, patients were mobilised and urinary catheters removed. No post-operative complications were recorded.
Patients were asymptomatic and denied any significant weight loss at their follow up appointment 12 weeks after discharge. Pathological characteristics of the tumours are summarized in Table 2; pathology revealed R0 resections with intact tumour capsule and margins free from tumour in all the patients.

All the patients follow UK national guidance on surveillance determined by the risk stratification used for this disease (7).

Patient 3 (Tables 1 and 2), who was the only one with high risk of recurrence, was started on Imatinib adjuvant therapy one month after the resection. Follow up CTs at six and eighteen months did not show any evidence of recurrence disease.

\section{Discussion}

Local excision of GISTs should be the treatment of choice, as these tumours rarely invade beyond the submucosal 
Table 2 GIST characteristics. Pathological features of resected tumours

\begin{tabular}{lcccccc}
\hline Patients & Mitosis/field $\left(5 \mathrm{~mm}^{2}\right)$ & cd117 & cd34 & dog1 & ki67 & Risk of progression \\
\hline 1 & 2 & + & + & + & Very low 1.9\% \\
2 & 1 & + & + & + & $1 \%$ & Low \\
3 & 6 & + & + & + & High \\
4 & 2 & + & + & + & Very low 1.9\% \\
\hline
\end{tabular}

GIST, gastro-intestinal stromal tumour.

layer. A negative (R0) oncological specimen marginnot necessarily wide-is considered enough to minimise recurrence rate. Lymph nodes harvesting is not pursued for these tumours, whereas it is important to preserve the capsule intact to limit spillage of neoplastic cells (1).

Laparoscopy offers the possibility for a limited and less invasive resection, and should be considered the alternative of choice $(2,8)$. However, staple lines can bleed and leak, and surgeons shall therefore aim at limiting their number within safety (6).

Compared to standard wedge resections $(3,9)$, our technique allow to save as much of the surrounding healthy tissue as possible, avoiding any narrowing or tortuosity of the remaining lumen. In order to preserve more gastric healthy tissue, intragastric approaches have also been described, where a gastrotomy is performed in the anterior gastric wall, then the tumour is exteriorized and stapled intragastrically, before another staple line (or suture) is used to close the gastrotomy $(5,10)$. The insertion of intragastric trocars have also been described (11). The advantage of the technique we propose compared to the above is not to leave an additional staple line inside the lumen of the stomach, which will not be visible at the end of the procedure and can potentially bleed intraluminally. Moreover, there is no need to oversew (12), use haemostatics (13) or tranexamic acid (13) in order to prevent/treat staple line bleeding.

The technique we propose is ideal to meet the abovementioned criteria and is applicable to tumours situated anywhere in the stomach, although technically it can be challenging to perform linear stapling for GISTs located in the immediate proximity of the gastro-esophageal junction (depending on their orientation). Even in the proximity of the GOJ or pylorus, it would compare favourably to wedge resections as a better way to maintain as much tissue and lumen behind as possible. However, the risk for stenosis and reflux esophagitis will have to be considered and appropriate pre-operating patients counselling will be necessary. Obviously, large sessile masses occupying more than $30 \%$ of the perimeter within these locations would require a more radical approach (including hand suturing and/or reconstruction) in order to avoid strictures in a low distensibility district.

Considering the rarity their presentation, we hope codifying our experience, even after such a limited amount of cases, will be useful to treat intraluminal gastric GISTs for the surgical community worldwide.

\section{Limitations}

Endophytic GISTs are rare events and we can currently only present a small initial case series of patients for which this technique was ideal. Moreover, tumours situated $<2 \mathrm{~cm}$ from the gastro-esophageal junction might prove difficult to resect using a linear stapler. Nevertheless, compared to standard wedge resection, this approach, which preserves as much tissue as possible, can be used to resect tumours closer to the OGJ (or pylorus).

\section{Conclusions}

Single staple line, tissue-preserving resection is a valuable way to surgically treat endophytic gastric GISTs. The technique can be routinely applied in laparoscopic and open surgery to minimise the risk of postoperative morbidity associated with multiple staple lines (such as endoluminal bleeding) as well as tumour cells dissemination.

\section{Acknowledgments}

This video was presented at the association of upper gastro intestinal surgeons 22nd annual conference in Liverpool (UK) in September 2019.

Funding: None. 


\section{Footnote}

Reporting Checklist: The authors have completed the AME Case Series reporting checklist. Available at https://jovs. amegroups.com/article/view/10.21037/jovs-20-103/rc

Peer Review File: Available at https://jovs.amegroups.com/ article/view/10.21037/jovs-20-103/prf

Conflicts of Interest: Both authors have completed the ICMJE uniform disclosure form (available at https://jovs. amegroups.com/article/view/10.21037/jovs-20-103/coif). The authors have no conflicts of interest to declare.

Ethical Statement: The authors are accountable for all aspects of the work in ensuring that questions related to the accuracy or integrity of any part of the work are appropriately investigated and resolved. All procedures performed in this study were in accordance with the ethical standards of the institutional and/or national research committee(s) and with the Helsinki Declaration (as revised in 2013). Written informed consent was obtained from the patients.

Open Access Statement: This is an Open Access article distributed in accordance with the Creative Commons Attribution-NonCommercial-NoDerivs 4.0 International License (CC BY-NC-ND 4.0), which permits the noncommercial replication and distribution of the article with the strict proviso that no changes or edits are made and the original work is properly cited (including links to both the formal publication through the relevant DOI and the license). See: https://creativecommons.org/licenses/by-nc-nd/4.0/.

\section{References}

1. Rubin BP, Heinrich MC, Corless CL. Gastrointestinal stromal tumour. Lancet 2007;369:1731-41.

2. Søreide K, Sandvik O, Soreide JA, et al. Global

doi: 10.21037/jovs-20-103

Cite this article as: Di Maggio F, Gossage JA. Single staple tissue preserving excision of intraluminal gastric GISTpreliminary case series. J Vis Surg 2022;8:41. epidemiology of gastrointestinal stromal tumours (GIST) a systematic review of population-based cohort studies. Cancer Epidemiol 2016;40:39-46.

3. Kakeji Y, Nakanoko T, Yoshida R, et al. Laparoscopic resection for gastrointestinal stromal tumours in the stomach. Surg Today 2012;42:554-8.

4. Xiong H, Wang J, Jia Y. Laparoscopic surgery versus open resections in patients with gastrointestinal stromal tumors: an updated systematic review and metanalysis. Am J Surg 2017;214:538-46.

5. Lee CM, Park S. Laparoscopic techniques and strategies for gastrointestinal GISTs. J Vis Surg 2017;3:62.

6. Silecchia G, Iossa A. Complications of staple line and anastomoses following laparosopic bariatric surgery. Ann Gastroenterol 2018;31:56-64.

7. Judson I, Bulusu R, udan S, et al. UK clinical practice guidelines for gastrointestinal stromal tumours (GIST). Clin Sarcoma Res 2017;7:6.

8. Karakousis GC, Singer S, Zheng J, et al. Laparoscopic versus open gastric resections for primary gastrointestinal stromal tumors (GISTs): a size-matched comparison. Ann Surg Oncol 2011;18:1599-605.

9. Hsiao CY, Yang CY, Lai IR, et al. Laparosopic resection for large gastric gastrointestinal stromal tumor (GIST): intermediate follow-up results. Surg Endosc 2015;29:868-73.

10. Hyung WJ, Lim JS, Cheong JH, et al. Laparoscopic resection of a huge intraluminal gastric submucosal tumor located in the anterior wall: eversion method. J Surg Oncol 2005;89:95-8.

11. Sahm M, Pross M, Lippert H. Intraluminal resection of gastric tumors using intragastric trocar technique. Surg Laparosc Endosc Percutan Tech 2011;21:e169-72.

12. Gentileschi P, Camperchioli I, D’Ugo S, et al. Staple-line reinforcement during laparoscopic sleeve gastrectomy using three different techniques: a randomized trial. Surg Endosc 2012;26:2623-9.

13. Chakravartty S, Sarma R, Chang A, et al. Staple Line Bleeding in Sleeve Gastrectomy-a Simple and CostEffective Solution. Obes Surg 2016;26:1422-8. 